\title{
MicroRNA: a bridge from $H$. pylori infection to gastritis and gastric cancer development
}

\author{
Jovanny Zabaleta ${ }^{1,2 *}$ \\ ${ }^{1}$ Department of Pediatrics, Louisiana State University Health Sciences Center, New Orleans, LA, USA \\ ${ }^{2}$ Stanley S. Scott Cancer Center, Louisiana State University Health Sciences Center, New Orleans, LA, USA
}

\section{Edited by:}

Peng Jin, Emory University School of

Medicine, USA

Reviewed by:

Yuichiro Watanabe, University of Tokyo, Japan

Bo Chen, Georgia Health Sciences University, USA

\section{*Correspondence:}

Jovanny Zabaleta, Department of Pediatrics and Stanley S. Scott Cancer Center, 533 Bolivar Street, CSRB 455, New Orleans, LA 70112, USA. e-mail: jzabal@Isuhsc.edu
Helicobacter pylori (H. pylori) infection is a recognized risk factor for gastric cancer. The disease is one of the most common in the world and explains for a significant number of cancer cases and cancer-associated deaths worldwide. H. pylori infection induces huge array of responses at the gastric epithelial cells and the immune system, inducing both pro- and anti-inflammatory molecules that are intended to either perpetuate or control the infection. Despite the strong immune response, the infection is not cleared and can persist mostly without causing major significant discomfort in the human host. Among the mediators induced in response to the infection, microRNA (miRNA) have the potential to play a major impact on the outcome of the bacteria-host interaction. These miRNA are small 18-24 nucleotide long nucleotide molecules that can interact with mRNA molecules and block their translation into proteins or induce their degradation. Many efforts have been put into the generation of miRNA profiles and their role in gastric cancer. This has led to the identification of miRNA associated with promoting the inflammatory response initiated by the $H$. pylori infection, increasing the malignant progression of the gastric epithelium, and enhancing the invasiveness and migratory capacity of cancer cells. However, at the same time, several miRNA have been associated with events that are totally opposite, leading to reduced inflammation, inhibition of malignancy and increased apoptosis of transformed cells. In summary, as it is in many other examples, the role played by miRNA in gastric cancer is the results of a delicate balance between pro- and anti-cancer miRNA, and this balance is modified by the interaction of many players, many of which are still waiting to be discovered.

Keywords: microRNA, Helicobacter pylori, gastric cancer, inflammation, gastritis

\section{INTRODUCTION}

According to the American Cancer Society (ACS), cancer is the second most common death cause in the United States ${ }^{1}$. Even though the survival rate (up to 5 -years) has improved tremendously over the last decades, it is expected that more that 1.5 million Americans will die to cancer in 2012 (Siegel et al., 2012). The incidence and mortality of gastric cancer has followed that of most cancers but still more than 10,000 deaths are expected to happened in 2012 (1.3\% of all cancer cases and $7.5 \%$ of digestive system cancers; Siegel et al., 2012). According to the Surveillance Epidemiology and End Results (SEER) ${ }^{2}$, gastric cancer is a disease of disparities, in terms of incidence and mortality, with African American men and women having the highest incidence and mortality rates of gastric cancer when compared to other races/ethnic groups. In addition, males from all ethnicities have higher incidence and mortality rates than females (see text footnote 2 ). There are several theories to explain these differences and based on several facts, it seems that estrogens are important modulators of gastric cancer risk (Camargo et al., 2012). Additional disparities in gastric cancer

${ }^{1}$ http://www.cancer.org

${ }^{2} \mathrm{http}: / /$ seer.cancer.gov/statfacts/html/stomach.html incidence and mortality rates are observed by geographic region with Japan and China having more than 20 cases of gastric cancer and North America presenting less than 10 cases per 100,000 individuals (Parkin, 2004; Parkin et al., 2005). All these observations led to the idea that environmental factors, including diet, play a major role in gastric cancer risk. However, recent findings have suggested a significant role of the genetic background in gastric cancer susceptibility. There have been plenty of publications showing association of single nucleotide polymorphisms (SNP) and risk of gastric cancer. We have shown also that these SNPs may serve as biomarkers of risk even at earlier stages, during the progression of inflammatory to malignant gastric stages (Zabaleta et al., 2006, 2008; Zabaleta, 2012). Identifying early markers of risk of GC is crucial because the disease has one of the highest rates of mortality worldwide. However, this task has been complicated by several factors, including difficulties for tissue collection (which is generally obtained by gastric biopsies); the presence of millions of SNPs in the genome and the lack of studies determining the degree of interactions among them; the time-dependent expression of genes which leads to misinterpretation of gene profiles; and very especially, the lack of studies validating genomic profiles generated from tissue samples in more easily obtained samples, 
like blood or urine, making replication of results less invasive and less hazardous and stressful for the patient.

\section{microRNA}

Since its discovery, microRNA (miRNA) added a new chapter in the study of gene regulation. It was initially observed that the expression of the heterochronic protein, those that control temporal development, Lin-14 during the development of Caenorhabditis elegans (C. elegans) lead to a temporal expression of several cell lineages (Ruvkun and Giusto, 1989). This temporal expression of Lin-14 protein leading to different genotypes suggested a strong regulation in the gene encoding its expression, Lin-14. It was later discovered that the expression of Lin-14 protein was downregulated at the post-transcriptional level by two products of the gene Lin-4, another heterochronic gene, whose products bind to the untranslated (UTR) $3^{\prime}$ region of the Lin-14 gene (Wightman et al., 1993). In an interesting series of papers published in the same issue of Science Magazine, three back-to-back papers showed that these small RNA molecules were present in organisms other than C. elegans, and the authors coined the term miRNA for them (Lagos-Quintana et al., 2001; Lau et al., 2001; Lee and Ambros, 2001). These miRNA result from the activity of two RNase III, Drosha, and Dicer, that process the primary miRNA into mature miRNA of 18-24 nucleotides that mediate inhibition of translation or degradation of messenger RNA (mRNA; Bartel, 2004) by base mispairing with mRNA (RNAi; Olsen and Ambros, 1999), giving the miRNAs a broad potential to regulate gene expression (Bartel and Chen, 2004). However, the degree of specificity for the binding of the miRNA with its target mRNA seems to be given by the first nine $5^{\prime}$ nucleotides (seed nucleotides) of the miRNA and their complementary $3^{\prime}$ untranslated regions $\left(3^{\prime} \mathrm{UTR}\right)$ in their targets (Moss et al., 1997; Reinhart et al., 2000; Kiriakidou et al., 2004; Vella et al., 2004).

\section{miRNA NOMENCLATURE}

The criteria for the identification of nucleotide sequences as miRNA were consented by a group of experts on the topic (Ambros et al., 2003). These researchers delineated certain characteristics that, except for some specific conditions, should be met by the sequence to be considered a miRNA, including the detection of a $\sim 22$ nt RNA molecule, identification of that molecule on a pool of cDNA made from RNA with specified sizes, the presence of a hairpin, phylogenetic conservation of the molecule and its precursor, and increased expression of the precursor RNA molecules in the absence of Dicer (Ambros et al., 2003). miRNAs are named based on several criteria, including: three or four letters to designate species (e.g., hsa for Homo sapiens); mature miRNAs are given the designation of "miR" while precursor sequences are named "mir"; sequential numbers; miRNAs that differ in only one or two nucleotides are given letter suffixes, i.e., mmu-miR-10a and mmu-miR-10b; if two different miRNAs are generated from the opposite arms of the hairpin are named with an additional suffix indicating the $5^{\prime}$ or the $3^{\prime}$ where the miRNA is generated from, i.e., hsa-miR-140-5p and hsa-miR-140-3p; in addition, when two miRNAs originate from opposite arms of the hairpin, the one with reduced expression is annotated with an asterisk (*; Ambros et al., 2003; Griffiths-Jones, 2005; Griffiths-Jones et al., 2006, 2008).

\section{MIRNA AND HELICOBACTER PYLORI INFECTION}

Among several factors, infection with Helicobacter pylori $(H$. pylori) pylori is considered to be a crucial event associated with risk of gastric cancer. Such is the importance of the infection in the inflammation that leads to gastric cancer that $H$. pylori has been classified as a Type I carcinogen by the International Agency for Research in Cancer (IARC; IARC, 1994). After infection to the gastric mucosa, $H$. pylori injects the product of the cytotoxinassociated gene (cag; CagA) into the gastric epithelial cells by a type IV secretion system (Backert et al., 2000; Odenbreit et al., 2000). Once there, CagA is phosphorylated (Stein et al., 2002) and induces a cascade of kinases activation leading to cellular changes (Higashi et al., 2002) and production of inflammatory cytokines (Orsini et al., 2000; Lai et al., 2011). Interestingly, using an in vitro system, it was shown that CagA induces hsa-miR-584 and hsa-miR-1290 in a NFK $\beta$ and Erk 1/2 dependent manner, respectively (Zhu et al., 2012). Another set of experiments has shown that after $H$. pylori infection there is a strong induction of hsa-miR-155 which inhibits the production of the potent proinflammatory cytokine IL8, through the inhibition of the NFк $\beta$ pathway by interacting with the $3^{\prime}$-UTR of the Iк $\beta$ kinase (Xiao et al., 2009; reviewed in Ma et al., 2011). Interestingly, in addition to hsa-miR-155, H. pylori infection also induced hsa-miR-146a (Xiao et al., 2009). This miRNA, in addition to hsa-miR-155 and hsa-miR-132, is produced in response to inflammatory stimulus like LPS (Taganov et al., 2006). Interestingly, similar to hsa-miR155 , miR-146 also regulates the NFк $\beta$ pathway by targeting TRAF6 and IRAK1 (Taganov et al., 2006; Liu et al., 2010). Through the regulation of TRAF6 and IRAK1, hsa-miR-146a modulates the inflammatory response induced by $H$. pylori by reducing the levels of IL8, MIP-3 $\alpha$, and GRO- $\alpha$ (Liu et al., 2010), suggesting that this miRNA plays an essential role in the control of the inflammatory response to $H$. pylori and possibly in the limitation of tissue damage observed in patients with gastritis and gastric cancer. In addition, hsa-miR-146a also regulates the expression of the PTGS2 gene (Liu et al., 2012b), which produces prostaglandin E2 that has been associated with $H$. pylori infection and concomitant infiltration of inflammatory cells to the gastric mucosa (Fu et al., 1999; McCarthy et al., 1999). As a quick reference, the association of several miRNA with $H$. pylori infection, gastritis, and gastric cancer is shown in a summarized way in Table $\mathbf{1}$.

\section{miRNA AND GASTRIC INFLAMMATORY STAGES}

Helicobacter pylori infection may last many years without inducing any type of gastric discomfort to its human host. Even though between 1 and $3 \%$ of infected people develop gastric cancer (Uemura et al., 2001; Suerbaum and Michetti, 2002; Wroblewski et al., 2010), the majority of infected individuals develop a continuous and progressive chronic inflammatory process initiated by non-atrophic gastritis and followed by multifocal atrophic gastritis, intestinal metaplasia, and dysplasia; the latter is considered the truly precancerous stage of the cascade (Correa et al., 1975; Zabaleta et al., 2006; reviewed in Zabaleta, 2012). The rate of change to more advanced gastric lesions is higher than the rate of regression (Correa et al., 1990). Even though pathological features clearly distinguish between each inflammatory stage, the molecular signatures of these transitions have not being explored and the 
Table 1 | Association of several miRNA with gastric lesions, from $\boldsymbol{H}$. pylori infection to gastric cancer.

\begin{tabular}{|c|c|c|}
\hline hsa-miR-\# & Observation & Reference \\
\hline 9, 146a, 155, 650, 96, 204 & Chronic active gastritis (NAG) & Lario et al. (2012) \\
\hline $21,223,218,25$ & H. pylori infection, gastric cancer & Li et al. (2012a) \\
\hline $155,146 a$ & Modulation of IL8, MIP3a, GRO-a, Reduced PTGS2 in H. pylori infection & $\begin{array}{l}\text { Liu et al. (2010), Liu et al. (2012b), } \\
\text { Xiao et al. (2009) }\end{array}$ \\
\hline $103,200 b, 200 c, 375,532$ & H. pylori-induced gastric inflammation & Isomoto et al. (2012) \\
\hline let-7 & Induced by CagA, accumulation of Ras & Hayashi et al. (2012) \\
\hline 17,2021223 & $\begin{array}{l}\text { Reduced in metaplastic and non-metaplastic cancerous glands after } H \text {. pylori } \\
\text { eradication }\end{array}$ & Shiotani et al. (2012) \\
\hline 17,204 & Increased after $H$. pylori eradication & Shiotani et al. (2012) \\
\hline $155,584,1290$ & Effect on severity of gastritis and presence of more advanced gastric lesions & Oertli et al. (2011), Zhu et al. (2012) \\
\hline 150 & $\begin{array}{l}\text { Increased in gastric cancer tissues; induces cell migration and invasion by reducing } \\
\text { the expression of EGR2 }\end{array}$ & Wu et al. (2010) \\
\hline
\end{tabular}

underlying mechanisms are unknown. It has been shown that the level of the pro-inflammatory cytokines IL1 $\beta$, IL6, IL8, and TNF $\alpha$ were positively correlated with the level of chronic gastritis but that correlation disappear in the presence of gastric atrophy and was inverse, for IL6 and IL8, in intestinal metaplasia (Isomoto et al., 2012). Interestingly, the levels of these cytokines were, in general, inversely correlated with the levels of several miRNA in the gastric mucosa. For example, the levels of miRNA let-7b were inversely correlated $(-0.59)$ with IL1B levels $(p<0.005)$ while hsa-miRNA103 correlated with IL6 $(-0.612, p<0.005)$, hsa-miR-375 with IL8 $(-0.469 ; p<0.05)$, and hsa-miR-200a with TNFA $(-0.606$; $p<0.005$; Isomoto et al., 2012). A profile of several miRNA was associated with reduction of all inflammatory cytokines, suggesting a common mechanism for the control of the expression of these inflammatory mediators (Isomoto et al., 2012). Interestingly, hsa-miR-155 deficient mice present reduced gastritis when compared to wild type mice (Oertli et al., 2011). These responses are associated with increased numbers of $H$. pylori CFU in the stomachs of infected hsa-miR-155 deficient mice and reduced CD4+ T-cell response evidenced by low production of IFN $\gamma$ and IL17 (Oertli et al., 2011). After a long follow-up, mice over expressing hsa-miR-584 and hsa-miR-1290 showed changes associated with gastric intestinal metaplasia including the appearance of colonic epithelium and colonic markers (Muc-2; Zhu et al., 2012), suggesting a role of these two miRNA in the development of more advanced gastric lesions. However, the role played by $H$. pylori, if any, was not determined in this in vivo follow-up. It is possible that the presence of $H$. pylori infection may shorten the time for the appearance of the epithelial abnormalities. However, even after eradication of $H$. pylori with a triple antibiotic treatment (amoxicillin, clarithromycin, and pump inhibitors) for a 7-day period, the levels of known oncogenic miRNA, including hsa-miR-21, hsamiR-25, and hsa-miR-93, did not change (Shiotani et al., 2012). In contrast, the levels of tumor-suppressor miRNA, including let7 and hsa-miR-204, increased after eradication (Shiotani et al., 2012). These results suggest that after infection and eradication of $H$. pylori, some underlying processes may continue that promote tissue damage and lead to gastric malignancy. In addition, it is also suggested that more than a single isolated response, the articulated and balanced reaction to the infection and to the inflammatory process dictates the outcome of the cascade initiated by the $H$. pylori infection. In addition to the inflammatory cascade associated with the development of gastric adenocarcinoma, several miRNA have been linked to $H$. pylori-induced mucosal associated lymphoid tissue (MALT) lymphomas. Using an array of 376 miRNA Thorns et al. (2012) found 41 miRNA associated with changes from normal gastric mucosa to gastritis and to MALT. Interestingly, the levels of some of these miRNA seem to change in response to the infiltration of lymphocytes or the presence of $H$. pylori while only a few (hsa-miR-150, hsa-miR-550, hsa-miR-124a, hsa-miR-518b, and hsa-miR-539) were associated with lymphoma and presented a steady increase from gastritis to MALT (Thorns et al., 2012). Taken together these results suggest that miRNA may be modulating pathways associated with differential outcomes in response to a common trigger, infection with $H$. pylori. This supports the concept about universality of the miRNA responses and opens up the possibility of more efficacious and global treatments for illnesses with common origins.

\section{miRNA AND GASTRIC CANCER}

It has been shown that the distribution of miRNAs on the human genome is non-random but rather, a significant fraction of them are located on chromosomal regions known as "fragile sites" and on genomic regions associated with cancer (Calin et al., 2004). In fact, according to the same report, the incidence of miRNA in these fragile sites is more than ninefold higher than in "nonfragile" regions (Calin et al., 2004). Due to their ability to interact with mRNA, a single miRNA can act as either tumor-suppressors or oncogenes, meaning that a miRNA can be classified as tumorsuppressor- or onco-miRNA, depending on the context of their expression, as has been shown for the miRNA cluster miR-1792 (He et al., 2005; O'Donnell et al., 2005). Over expression of onco-miRNAs may target certain tumor-suppressor genes and allow the activity of oncogenes and their targets. On the contrary, over expression of tumor-suppressor miRNA would limit the transcription of genes associated with tumorigenesis, cell division, migration and invasion, and metastasis. In this sense, for example, it has been shown that hsa-miR-135a promotes metastasis in breast cancer cell lines by direct interaction with HOXA10 gene, which acts as a metastasis suppressor in this cancer model (Chu 
et al., 2004; Chen et al., 2012). Due to the dual role of miRNA in cancer and to the dynamic nature of these gastric lesions, it would be recommended to establish the association with disease using several miRNA, or miRNA profiles, rather than doing it with individual miRNA. An early miRNA profile in gastric cancer showed that stomach tissues have a specific miRNA signature that is similar to that of pancreas, colon, and prostate cancers but different from that of breast and lung cancer (Volinia et al., 2006).

The association of specific miRNA or miRNA signatures with gastric cancer is at several levels. One very frequent feature found is that miRNA modify the capacity of gastric cancer cells to proliferate, migrate, and invade. Using in vitro and in vivo systems several authors have shown that miRNAs act as inductors of cell proliferation and inhibitors of apoptosis by interacting with and inhibiting the expression of known tumor-suppressor genes. Wu et al. (2010) showed that overexpression of hsa-miR-150 increases the proliferation of gastric cell lines, as compared to non-treated cells or cells treated with hsa-miR-150 antagonists. hsa-miR-150 transfected cell lines were also able to induce tumor formation in nude mice. Interestingly, hsa-miR-150 was increased in gastric cancer cell lines as well as in gastric cancer tissues, while its expression was reduced in normal adjacent and distant tissues (Wu et al., 2010). Later analysis showed that the effect of hsa-miR-150 was associated with reduced expression of the gene EGR2 (Wu et al., 2010), which has been described as a tumor-suppressor (Unoki and Nakamura, 2001). The EGR2 gene seems to be one of the mediators of the antitumor effects of PTEN (Matsushima-Nishiu et al., 2001; Unoki and Nakamura, 2001), which in turns, is reduced by the interaction with another miRNA, hsa-miR-21 (Zhang et al., 2012a). On the other hand, Zhang et al. (2012b) have described an increased expression of hsa-miR-181a in gastric tumors, as compared to normal tissues. This miRNA interacts with the $3^{\prime}$-UTR of the tumor-suppressor gene $K L F$, which is reduced in the same gastric tissues where miR-181a was measured, and is able to inhibit apoptosis of gastric cell lines (Zhang et al., 2012b). A recent publication (Zhu et al., 2010) shows that miRNA let-7a expression is significantly reduced in gastric epithelial cancer cells when compared to normal cells, especially in samples from patients with lymph node metastasis.

After being able to maintain certain level of cellular proliferation, cancer cells must gain the capacity to cross the basal cellular layers of the epithelia and get into the blood stream to metastasize to local lymph nodes and farther tissues. In two different approaches researchers have shown an important role for the gene inhibitor of growth (ING4) which is targeted by hsamiR-650 and hsa-miR-622 and this in turn, seems to be associated with increased invasion/migration of gastric cell lines in vitro and promote metastasis in nude mice (Zhang et al., 2010; Guo et al., 2011). In synthesis, the success of a gastric cancer cell to invade and become metastatic depends on the ability of that cell to promote or down-regulate the expression of proteins involved in cell cycle, adhesion, cell-to-cell contact, among other things. The balance between miRNA with activities pro- and anti-tumorigenesis may in part determine the final outcome and define the fate of the tumor. So, there are miRNA profiles that promote tumor growth including hsa-miR-622, hsa-miR-650, hsa-miR-223, hsamiR-21, and hsa-miR-181a, among others (Zhang et al., 2010, 2012a,b; Guo et al., 2011; Li et al., 2011b); while hsa-miR-107, $-145,-495,-551 a$, let-7f, -218 , and -610, among others, inhibit cell invasion and metastasis (Tie et al., 2010; Li et al., 2011a, 2012b; Liang et al., 2011; Feng et al., 2012; Gao et al., 2012; Wang et al., 2012).

\section{mIRNA AND ITS ROLE AS BIOMARKERS AND PREDICTORS OF GASTRIC CANCER}

Compared with the much higher number of mRNA, about 1,000 miRNA have been validated in humans, making feasible the generation of genetic profiles, with microarrays and high throughput sequencing, to associate with disease and disease outcome, or to identify possible biomarkers. In addition, due to its size, miRNA are very stable in biological fluids facilitating the profiling with non-invasive methods. After creating miRNA profiles in gastric cancer, colorectal cancer, and healthy controls, 7 miRNA were identified as specific for gastric cancer (Liu et al., 2012a). However, after validating these 7 miRNA in an independent set of samples, miR-187*, miR-371-5p, and miR-378 remained significantly associated with gastric cancer serum samples (Liu et al., 2012a). Further analysis revealed that hsa-miR-378 had a better biomarker potential and this was corroborated by showing that the level of hsa-miR-378 started to increase very early during the cancer development making it a possible early detection marker for gastric cancer (Liu et al., 2012a). Additional studies have identified several other miRNA that could serve as biomarkers and predictors of gastric cancer (Liu et al., 2011; Li et al., 2012a; Song et al., 2012). The differences observed in the profiles may be related to several things, including ancestry, density of the platform used for the profiling (i.e., microarray, TaqMan arrays), which may allow for lower or higher input of sequences and therefore, limit the probability of identifying specific miRNA. Whatever the technology used, it is clear that miRNA profiling is a potent tool that can be used to improve both diagnosis and prognosis in gastric cancer. The current knowledge of the miRNA role in the pathogenesis of gastric cancer make these as potential targets to either improve therapeutic options currently in use, or to devise new strategies for the treatment of the disease. These treatments have to be directed to at least two things, to reduce the malignant process that lead to hyper-proliferation of gastric cells and are associated to malignant transformation, and to reduce the inflammatory response that promote the influx of immune cells into the gastric mucosa. In addition, it is very possible that $H$. pylori has its own set of miRNA that can affect the immune response of the host in order to increase the chances of perpetuating its infection.

\section{CONCLUSION}

microRNA profiles have been established, and most probably will be used as molecular targets to modify the interaction of $H$. pylori with gastric cells and to reduce the inflammation and cellular malignancy that may lead to gastric cancer. Among profiles of mRNA, methylation ( $\mathrm{cpG}$ ), genome wide association studies (GWAS), miRNA profiles have the highest potential to successfully become widely used to reach the goal of "personalized medicine" by which, a patient is to be medically treated according to his/her 
genetic profile. These profiles, it is expected, would classify and predict the outcome of a disease better than traditional techniques, as well as dictate the steps to follow in order to better treat that specific patient.

\section{REFERENCES}

Ambros, V., Bartel, B., Bartel, D. P., Burge, C. B., Carrington, J. C., Chen, X., et al. (2003). A uniform system for microRNA annotation. RNA 9, 277-279.

Backert, S., Ziska, E., Brinkmann, V., Zimny-Arndt, U., Fauconnier, A., Jungblut, P. R., et al. (2000). Translocation of the Helicobacter pylori CagA protein in gastric epithelial cells by a type IV secretion apparatus. Cell. Microbiol. 2, 155-164.

Bartel, D. P. (2004). MicroRNAs: genomics, biogenesis, mechanism, and function. Cell 116, 281-297.

Bartel, D. P., and Chen, C. Z. (2004). Micromanagers of gene expression: the potentially widespread influence of metazoan microRNAs. Nat. Rev. Genet. 5, 396-400.

Calin, G. A., Sevignani, C., Dumitru, C. D., Hyslop, T., Noch, E., Yendamuri, S., et al. (2004). Human microRNA genes are frequently located at fragile sites and genomic regions involved in cancers. Proc. Natl. Acad. Sci. U.S.A. 101, 2999-3004

Camargo, M. C., Goto, Y., Zabaleta, J., Morgan, D. R., Correa, P., and Rabkin, C. S. (2012). Sex hormones, hormonal interventions, and gastric cancer risk: a meta-analysis. Cancer Epidemiol. Biomarkers Prev. 21, 20-38.

Chen, Y., Zhang, J., Wang, H., Zhao, J., $\mathrm{Xu}, \mathrm{C}$., Du, Y., et al. (2012). miRNA135 a promotes breast cancer cell migration and invasion by targeting HOXA10. BMC Cancer 12:111. doi:10.1186/1471-2407-12-111

Chu, M. C., Selam, F. B., and Taylor, H. S. (2004). HOXA10 regulates p53 expression and matrigel invasion in human breast cancer cells. Cancer Biol. Ther. 3, 568-572.

Correa, P., Haenszel, W., Cuello, C., Tannenbaum, S., and Archer, M. (1975). A model for gastric cancer epidemiology. Lancet 2, 58-60.

Correa, P., Haenszel, W., Cuello, C., Zavala, D., Fontham, E., Zarama, G., et al. (1990). Gastric precancerous process in a high risk population: cohort follow-up. Cancer Res. 50, 4737-4740.

Feng, L., Xie, Y., Zhang, H., and Wu, Y. (2012). miR-107 targets cyclin-dependent kinase 6 expression, induces cell cycle G1 arrest and inhibits invasion in gastric cancer cells. Med. Oncol. 29, 856-863.
Fu, S., Ramanujam, K. S., Wong, A. Fantry, G. T., Drachenberg, C. B., James, S. P., et al. (1999). Increased expression and cellular localization of inducible nitric oxide synthase and cyclooxygenase 2 in Helicobacter pylori gastritis. Gastroenterology 116, 1319-1329.

Gao, P., Xing, A. Y., Zhou, G. Y., Zhang, T. G., Zhang, J. P., Gao, C., et al. (2012). The molecular mechanism of microRNA-145 to suppress invasion-metastasis cascade in gastric cancer. Oncogene. doi:10.1038/onc.2012.61

Griffiths-Jones, S. (2005). Annotating non-coding RNAs with Rfam. Curr. Protoc. Bioinformatics. 12, Unit-12.5

Griffiths-Jones, S., Grocock, R. J., van, D. S., Bateman, A., and Enright, A. J. (2006). miRBase: microRNA sequences, targets and gene nomenclature. Nucleic Acids Res. 34, D140D144.

Griffiths-Jones, S., Saini, H. K., van, D. S., and Enright, A. J. (2008). miRBase: tools for microRNA genomics. Nucleic Acids Res. 36, D154-D158.

Guo, X. B., Jing, C. Q., Li, L. P., Zhang, L., Shi, Y. L., Wang, J. S., et al. (2011). Down-regulation of miR622 in gastric cancer promotes cellular invasion and tumor metastasis by targeting ING1 gene. World J. Gastroenterol. 17, 1895-1902.

Hayashi, Y., Tsujii, M., Wang, J., Kondo, J., Akasaka, T., Jin, Y., et al. (2012). CagA mediates epigenetic regulation to attenuate let-7 expression in Heliesis. Gut. doi:10.1136/gutjnl-2011301625

He, L., Thomson, J. M., Hemann, M. T., Hernando-Monge, E., Mu, D., Goodson, S., et al. (2005). A microRNA polycistron as a potential human oncogene. Nature 435, 828-833.

Higashi, H., Tsutsumi, R., Muto, S., Sugiyama, T., Azuma, T., Asaka, M., et al. (2002). SHP-2 tyrosine phosphatase as an intracellular target of Helicobacter pylori CagA protein. Science 295, 683-686.

IARC. (1994). Monograph on the Evaluation of Carcinogenic Risks to Humans: Schistosomes, Liver flukes and Helicobacter pylori. World Health Organization, Lyon, 1-241.

Isomoto, H., Matsushima, K., Inoue, N., Hayashi, T., Nakayama, T., Kunizaki, M., et al. (2012). Interweaving cobacter pylori-related carcinogen-

\section{ACKNOWLEDGMENTS}

This work was supported in part by COBRE Grant number 149740220B and by the Louisiana Cancer Research Consortium (LCRC).

microRNAs and proinflammatory cytokines in gastric mucosa with reference to H. pylori infection. J. Clin. Immunol. 32, 290-299.

Kiriakidou, M., Nelson, P. T., Kouranov, A., Fitziev, P., Bouyioukos, C., Mourelatos, Z., et al. (2004). A combined computationalexperimental approach predicts human microRNA targets. Genes Dev. 18, 1165-1178.

Lagos-Quintana, M., Rauhut, R., Lendeckel, W., and Tuschl, T. (2001). Identification of novel genes coding for small expressed RNAs. Science 294, 853-858.

Lai, C. H., Wang, H. J., Chang, Y. C., Hsieh, W. C., Lin, H. J., Tang, C. H., et al. (2011). Helicobacter pylori CagA-mediated IL-8 induction in gastric epithelial cells is cholesteroldependent and requires the $\mathrm{C}$ terminal tyrosine phosphorylationcontaining domain. FEMS Microbiol. Lett. 323, 155-163.

Lario, S., Ramirez-Lazaro, M. J., Aransay, A. M., Lozano, J. J., Montserrat, A., Casalots, A., et al. (2012). microRNA profiling in duodenal ulcer disease caused by Helicobacter pylori infection in a Western population. Clin. Microbiol. Infect. 18, E273-E282.

Lau, N. C., Lim, L. P., Weinstein, E. G., and Bartel, D. P. (2001). An abundant class of tiny RNAs with probable regulatory roles in Caenorhabditis elegans. Science 294, 858-862.

Lee, R. C., and Ambros, V. (2001). An extensive class of small RNAs in Caenorhabditis elegans. Science 294, 862-864.

Li, B. S., Zhao, Y. L., Guo, G., Li, W., Zhu, E. D., Luo, X., et al. (2012a). Plasma microRNAs, miR223, miR-21 and miR-218, as novel potential biomarkers for gastric cancer detection. PLoS ONE 7:e41629. doi:10.1371/journal.pone.0041629

Li, Z., Cao, Y., Jie, Z., Liu, Y., Li, Y., Li, J., et al. (2012b). miR-495 and miR-55la inhibit the migration and invasion of human gastric cancer cells by directly interacting with PRL-3. Cancer Lett. 323, 41-47.

Li, X., Zhang, Y., Shi, Y., Dong, G., Liang, J., Han, Y., et al. (2011a). MicroRNA107 , an oncogene microRNA that regulates tumour invasion and metastasis by targeting DICER1 in gastric cancer. J. Cell Mol. Med. 15, 1887-1895.

Li, X., Zhang, Y., Zhang, H., Liu, X., Gong, T., Li, M., et al. (2011b). miRNA-223 promotes gastric cancer invasion and metastasis by targeting tumor suppressor EPB41L3. Mol. Cancer Res. 9, 824-833.

Liang, S., He, L., Zhao, X., Miao, Y., Gu, Y., Guo, C., et al. (2011). MicroRNA let-7f inhibits tumor invasion and metastasis by targeting MYH9 in human gastric cancer. PLoS ONE 6:e18409. doi:10.1371/journal.pone.0018409

Liu, H., Zhu, L., Liu, B., Yang, L., Meng, X., Zhang, W., et al. (2012a). Genome-wide microRNA profiles identify miR-378 as a serum biomarker for early detection of gastric cancer. Cancer Lett. 316, 196-203.

Liu, Z., Wang, D., Hu, Y., Zhou, G., Zhu, C., Yu, Q., et al. (2012b). MicroRNA-146a negatively regulates PTGS2 expression induced by Helicobacter pylori in human gastric epithelial cells. J Gastroenterol. doi:10.1007/s00535-012-0609-9

Liu, R., Zhang, C., Hu, Z., Li, G., Wang, C., Yang, C., et al. (2011). A five-microRNA signature identified from genome-wide serum microRNA expression profiling serves as a fingerprint for gastric cancer diagnosis. Eur. J. Cancer 47, 784-791.

Liu, Z., Xiao, B., Tang, B., Li, B., Li, N., Zhu, E., et al. (2010). Up-regulated microRNA-146a negatively modulate Helicobacter pylori-induced inflammatory response in human gastric epithelial cells. Microbes Infect. 12, 854-863.

Ma, X., Becker Buscaglia, L. E., Barker, J. R., and Li, Y. (2011). MicroRNAs in NF-kappaB signaling. J. Mol. Cell Biol. 3, 159-166.

Matsushima-Nishiu, M., Unoki, M., Ono, K., Tsunoda, T., Minaguchi, T., Kuramoto, H., et al. (2001). Growth and gene expression profile analyses of endometrial cancer cells expressing exogenous PTEN. Cancer Res. 61, 3741-3749.

McCarthy, C. J., Crofford, L. J., Greenson, J., and Scheiman, J. M. (1999). Cyclooxygenase- 2 expression in gastric antral mucosa before and after eradication of Helicobacter pylori infection. Am. J. Gastroenterol. 94, 1218-1223. 
Moss, E. G., Lee, R. C., and Ambros, V. (1997). The cold shock domain protein LIN-28 controls developmental timing in C. elegans and is regulated by the lin-4 RNA. Cell 88, 637-646.

Odenbreit, S., Puls, J., Sedlmaier, B., Gerland, E., Fischer, W., and Haas, R. (2000). Translocation of Helicobacter pylori CagA into gastric epithelial cells by type IV secretion. Science 287, 1497-1500.

O’Donnell, K. A., Wentzel, E. A., Zeller, K. I., Dang, C. V., and Mendell, J. T. (2005). c-Myc-regulated microRNAs modulate E2F1 expression. Nature 435, 839-843.

Oertli, M., Engler, D. B., Kohler, E., Koch, M., Meyer, T. F., and Muller, A. (2011). MicroRNA-155 is essential for the $\mathrm{T}$ cell-mediated control of Helicobacter pylori infection and for the induction of chronic Gastritis and Colitis. J. Immunol. 187, 3578-3586.

Olsen, P. H., and Ambros, V. (1999). The lin-4 regulatory RNA controls developmental timing in Caenorhabditis elegans by blocking LIN-14 protein synthesis after the initiation of translation. Dev. Biol. 216, 671-680.

Orsini, B., Ciancio, G., Censini, S., Surrenti, E., Pellegrini, G., Milani, S., et al. (2000). Helicobacter pylori cag pathogenicity island is associated with enhanced interleukin-8 expression in human gastric mucosa. Dig. Liver Dis. 32, 458-467.

Parkin, D. M. (2004). International variation. Oncogene 23, 6329-6340.

Parkin, D. M., Bray, F., Ferlay, J., and Pisani, P. (2005). Global cancer statistics, 2002. CA Cancer J. Clin. 55, 74-108.

Reinhart, B. J., Slack, F. J., Basson, M., Pasquinelli, A. E., Bettinger, J. C., Rougvie, A. E., et al. (2000). The 21-nucleotide let-7 RNA regulates developmental timing in Caenorhabditis elegans. Nature 403, 901-906.

Ruvkun, G., and Giusto, J. (1989). The Caenorhabditis elegans heterochronic gene lin-14 encodes a nuclear protein that forms a temporal developmental switch. Nature 338, 313-319.

Shiotani, A., Uedo, N., Iishi, H., Murao, T., Kanzaki, T., Kimura, Y., et al. (2012). H. pylori eradication did not improve dysregulation of specific oncogenic miRNAs in intestinal metaplastic glands. J Gastroenterol. 47, 988-998.

Siegel, R., Naishadham, D., and Jemal, A. (2012). Cancer statistics, 2012. CA Cancer J. Clin. 62, 10-29.

Song, M. Y., Pan, K. F., Su, H. J., Zhang, L., Ma, J. L., Li, J. Y., et al. (2012). Identification of serum microRNAs as novel non-invasive biomarkers for early detection of gastric cancer. PLoS ONE 7:e33608. doi:10.1371/journal.pone.0033608

Stein, M., Bagnoli, F., Halenbeck, R., Rappuoli, R., Fantl, W. J., and Covacci, A. (2002). c-Src/Lyn kinases activate Helicobacter pylori CagA through tyrosine phosphorylation of the EPIYA motifs. Mol. Microbiol. 43, 971-980.

Suerbaum, S., and Michetti, P. (2002). Helicobacter pylori infection. $N$. Engl. J. Med. 347, 1175-1186.

Taganov, K. D., Boldin, M. P., Chang, K. J., and Baltimore, D. (2006). NF-kappaB-dependent induction of microRNA miR-146, an inhibitor targeted to signaling proteins of innate immune responses. Proc. Natl. Acad. Sci. U.S.A. 103, 12481-12486.

Thorns, C., Kuba, J., Bernard, V., Senft, A., Szymczak, S., Feller, A. C., et al. (2012). Deregulation of a distinct set of microRNAs is associated with transformation of gastritis into MALT lymphoma. Virchows Arch. 460, 371-377.

Tie, J., Pan, Y., Zhao, L., Wu, K., Liu, J., Sun, S., et al. (2010). MiR-218 inhibits invasion and metastasis of gastric cancer by targeting the robol receptor. PLoS Genet. 6:e1000879. doi:10.1371/journal.pgen.1000879

Uemura, N., Okamoto, S., Yamamoto, S., Matsumura, N., Yamaguchi, S., Yamakido, M., et al. (2001). Helicobacter pylori infection and the development of gastric cancer. $N$. Engl. J. Med. 345, 784-789.

Unoki, M., and Nakamura, Y. (2001). Growth-suppressive effects of BPOZ and EGR2, two genes involved in the PTEN signaling pathway. Oncogene 20, 4457-4465.

Vella, M. C., Choi, E. Y., Lin, S. Y., Reinert, K., and Slack, F. J. (2004). The C. elegans microRNA let-7 binds to imperfect let-7 complementary sites from the lin-41 3'UTR. Genes Dev 18, 132-137.

Volinia, S., Calin, G. A., Liu, C. G. Ambs, S., Cimmino, A., Petrocca F., et al. (2006). A microRNA expression signature of human solid tumors defines cancer gene targets. Proc. Natl. Acad. Sci. U.S.A. 103, 2257-2261.

Wang, J., Zhang, J., Wu, J., Luo, D., Su, K. Shi, W., et al. (2012). MicroRNA-610 inhibits the migration and invasion of gastric cancer cells by suppressing the expression of vasodilatorstimulated phosphoprotein. Eur. J. Cancer 48, 1904-1913.

Wightman, B., Ha, I., and Ruvkun, G. (1993). Posttranscriptional regulation of the heterochronic gene lin14 by lin- 4 mediates temporal pattern formation in C. elegans. Cell 75 , 855-862.

Wroblewski, L. E., Peek, R. M. Jr., and Wilson, K. T. (2010). Helicobacter pylori and gastric cancer: factors that modulate disease risk. Clin. Microbiol. Rev. 23, 713-739.

Wu, Q., Jin, H., Yang, Z., Luo, G., Lu, Y., Li, K., et al. (2010). MiR-150 promotes gastric cancer proliferation by negatively regulating the proapoptotic gene EGR2. Biochem. Biophys. Res. Commun. 392, 340-345.

Xiao, B., Liu, Z., Li, B. S., Tang, B., Li, W., Guo, G., et al. (2009). Induction of microRNA-155 during Helicobacter pylori infection and its negative regulatory role in the inflammatory response. J. Infect. Dis. 200, 916-925.

Zabaleta, J. (2012). Multifactorial etiology of gastric cancer. Methods Mol. Biol. 863, 411-435.

Zabaleta, J., Camargo, M. C., Piazuelo, M. B., Fontham, E., Schneider, B. G. Sicinschi, L. A., et al. (2006). Association of interleukin-1beta gene polymorphisms with precancerous gastric lesions in African Americans and Caucasians. Am. J. Gastroenterol. 101, 163-171.

Zabaleta, J., Schneider, B. G., Ryckman, K., Hooper, P. F., Camargo, M. C., Piazuelo, M. B., et al. (2008). Ethnic differences in cytokine gene polymorphisms: potential implications for cancer development. Cancer Immunol. Immunother. 57, 107-114.
Zhang, B. G., Li, J. F., Yu, B. Q., Zhu, Z. G., Liu, B. Y., and Yan, M. (2012a). microRNA-21 promotes tumor proliferation and invasion in gastric cancer by targeting PTEN. Oncol. Rep. 27, 1019-1026.

Zhang, X., Nie, Y., Du, Y., Cao, J., Shen, B., and Li, Y. (2012b). MicroRNA181a promotes gastric cancer by negatively regulating tumor suppressor KLF6. Tumour. Biol. 33, 1589-1597.

Zhang, X., Zhu, W., Zhang, J., Huo, S., Zhou, L., Gu, Z., et al. (2010). MicroRNA-650 targets ING4 to promote gastric cancer tumorigenicity. Biochem. Biophys. Res. Commun. 395, 275-280.

Zhu, Y., Jiang, Q., Lou, X., Ji, X., Wen, Z., Wu, J., et al. (2012). MicroRNAs up-regulated by CagA of Helicobacter pylori induce intestinal metaplasia of gastric epithelial cells. PLOS ONE 7:e35147. doi:10.1371/journal.pone.0035147

Zhu, Y. M., Zhong, Z. X., and Liu, Z. M. (2010). Relationship between let$7 \mathrm{a}$ and gastric mucosa cancerization and its significance. World $J$. Gastroenterol. 16, 3325-3329.

Conflict of Interest Statement: The author declares that the research was conducted in the absence of any commercial or financial relationships that could be construed as a potential conflict of interest.

Received: 04 September 2012; paper pending published: 04 October 2012; accepted: 28 November 2012; published online: 14 December 2012.

Citation: Zabaleta J (2012) MicroRNA: a bridge from $H$. pylori infection to gastritis and gastric cancer development. Front. Gene. 3:294. doi: 10.3389/fgene.2012.00294

This article was submitted to Frontiers in Non-Coding RNA, a specialty of Frontiers in Genetics.

Copyright (c) 2012 Zabaleta. This is an open-access article distributed under the terms of the Creative Commons Attribution License, which permits use, distribution and reproduction in other forums, provided the original authors and source are credited and subject to any copyright notices concerning any third-party graphics etc. 